\title{
The Quest for Sustainable Teaching Praxis: Opportunities and Challenges of Multidisciplinary and Multicultural Teamwork
}

\author{
Elli Doukanari ${ }^{1}$, Despo Ktoridou ${ }^{2}$, Leonidas Efthymiou ${ }^{3, *(\mathbb{D})}$ and Epaminondas Epaminonda ${ }^{2}$ \\ 1 Department of Languages and Literature, University of Nicosia, Nicosia 2417, Cyprus; \\ doukanari.e@unic.ac.cy \\ 2 Department of Management and MIS, University of Nicosia, Nicosia 2417, Cyprus; \\ ktoridou.d@unic.ac.cy (D.K.); epaminonda.n@unic.ac.cy (E.E.) \\ 3 Department of HTS Management, University of Nicosia, Nicosia 2417, Cyprus \\ * Correspondence: efthymiou.1@unic.ac.cy
}

check for updates

Citation: Doukanari, E.;

Ktoridou, D.; Efthymiou, L.;

Epaminonda, E. The Quest for

Sustainable Teaching Praxis:

Opportunities and Challenges of

Multidisciplinary and Multicultural

Teamwork. Sustainability 2021, 13,

7210. https://doi.org/10.3390/

su13137210

Academic Editor: Jordi Colomer Feliu

Received: 26 April 2021

Accepted: 23 June 2021

Published: 28 June 2021

Publisher's Note: MDPI stays neutral with regard to jurisdictional claims in published maps and institutional affiliations.

Copyright: (c) 2021 by the authors. Licensee MDPI, Basel, Switzerland. This article is an open access article distributed under the terms and conditions of the Creative Commons Attribution (CC BY) license (https:/ / creativecommons.org/licenses/by/ $4.0 /$ )

\begin{abstract}
This article investigates the prospect of implementing multidisciplinary and multicultural student teamwork (MMT), along with Case-based Learning (CBL) and Problem-based Learning (PBL), as a sustainable teaching practice. Based on a mixed-method approach, which includes direct observation (both physical and virtual), questionnaire distribution, and focus groups, the study reveals that MMT through CBL and PBL can both facilitate and hinder sustainable learning. Our findings show that while MMT enhances knowledge sharing, it also poses a wide range of challenges, raising questions about its social significance as a sustainable teaching practice. The study suggests the implementation of certain mechanisms, such as 'Teamwork Training' and 'Pedagogical Mentors', aiming to strengthen the sustainable orientation of MMT through CBL and PBL.
\end{abstract}

Keywords: sustainable education; sustainability; educational inclusion; multidisciplinary learning; multicultural learning; teamwork; learning platforms

\section{Introduction}

Education can be said to be part of an ongoing transition, which is comprised by opportunities and challenges [1]. Student mobility, social changes [2], educational technological advancements [3], increasing international orientation, and the expectations set by frameworks such as the 21st century skills, continuously alter the landscape of education. In the light of these changes, there is a growing interest by researchers and scholars for education with a more sustainable orientation [4]. Research on sustainable education examines a wide range of learning practices, methods, and strategies, and how they consider, adapt to, and meet the diverse needs of student cohorts. Research on sustainable education is also concerned with multicultural and multidisciplinary characteristics, which are central to the discussion agendas in Higher Education [5-8].

In this spirit, the current article adds to the growing body of sustainable education by testing empirically the five dimensions of teamwork, which are (a) Multidisciplinary and (b) Multicultural Teams (MMT) working through (c) Case-based Learning (CBL) and (d) Problem-based Learning (PBL), (e) both face-to-face and online. Previous research [5,6] has demonstrated how multidisciplinary as well as multicultural peer-learning occurs through CBL and PBL activities. Taking this literature as a point of departure, the current article extends the notion of teamwork by exploring MMT through the aforementioned activities in terms of sustainable education. MMT, CBL, and PBL are likely to be part of sustainable education as they improve students' awareness, critical thinking, and problem-solving skills to deal with real-world challenges. It has been widely documented in the existing literature that CBL and PBL as learning strategies encourage active participation; facilitate student collaboration, offering students the opportunity to test theory through practice; and enable students to come up with innovative solutions to problems [9]. 
However, how useful are case-based and problem-based activities in multicultural and multidisciplinary collaboration? How does the addition of technology (e.g., Google applications) in the teamwork process influence the learning experience; is it beneficial and meaningful? Which teamwork practices are really sustainable in a diversified and multidisciplinary context? How do diversified team formations respond to Problem-based Learning? By bringing the aforementioned five dimensions together, the article makes an original contribution to the literature of sustainable education. Using mixed methods, which include direct observation, questionnaire distribution, and focus-group interviews, the article explores the impact of MMT through CBL and PBL activities on critical and reflective practice. The article also adds to the existing literature in the field of intercultural and interdisciplinary learning, and to a wider effort to explore methods, practices, and developing technologies that meet the diverse needs of international student cohorts from various disciplines.

In the next section, the conceptual framework of Sustainable Education is reviewed, together with studies in the field of teamwork and case-based and problem-based activities. After that, the article presents the methodological underpinnings of the study, prior to discussing the results of the fieldwork. The article concludes with recommendations on a meaningful application of teaching practices, and how pragmatic realities in diverse student groups determine effective teaching.

\section{Sustainable Teaching Practices}

What is meant by sustainable education? What are the so-called sustainable teaching practices? In the literature, several accounts contribute to our understanding of sustainable education, which often focus on everyday teaching practices, learning strategies, and pedagogies. One approach concerns the so called 'sustainable feedback'; that is, feedback sought, asked, and provided by students instead of having teachers give the feedback without prior solicitation $[10,11]$. The main principle here is that students are equipped to become self-initiating seekers and users of information, which is vital for lifetime learning [12]. Similarly, for [13], feedback is sustainable, inasmuch as it places students in an active role in which they generate and use feedback from peers, themselves, or others. Students are encouraged to judge their own work, ask for feedback, and compare their own internal judgments thereof with the external feedback from others [14]. Based on this, students can plan further steps towards achieving learning objectives in subsequent tasks. While not everything characterized as feedback is effective, within this framework, sustainability stems from continuous dialogue between students and tutors of what feedback is, thus developing the necessary skills for it [13].

Another approach in sustainable education is linked to 'sustainable development'; that is, education helping students acquire knowledge, learning capacity, lifestyle, and values for sustainable development in society, economy, environment, and culture [8]. In this context, sustainable education entails a redirection away from traditional, teacher-centric education. It rather needs to link knowledge with actual world problems [15] through an inter-disciplinary and cross-disciplinary approach to developing the competencies needed for building a sustainable future $[16,17]$. Sustainable teaching practices and sustainable development are both seen as means of fostering the ideals of internationalization [4].

Sustainable education is also linked to the so called 'Sustainable Curricular'. Higher education institutions (HEI) perform periodical curricular reviews adhering to internal and external quality assurance systems. However, along with quality assurance and validation, [6] suggest the application of quality metrics to maintain academic program sustainability. More specifically, quality measurements, stemming from certain Key Performance Indicators (KPIs), provide the basis for rethinking curriculum and pedagogical strategies for developing sustainable higher education programs [16].

Moreover, sustainability is also linked to 'assessment' instruments. For instance, [18] explain how self-assessment, peer assessment, and co-assessment, as part of formative tasks, serve as means of sustainable evaluation. For the authors in [19], sustainable assessment 
is enhanced through collaborative evaluation strategies, such as self-evaluation and coevaluation among team members while performing tasks. To the extent that it includes peer and/or team collaboration, certain assessments can be seen as sustainable. According to [12], sustainable assessments also differ from the usual formative tasks as they help students develop life-long learning evaluation skills.

Another approach to sustainable education explores existing teaching practices through technological advancements. This framework is also known as 'Technology-enhanced Learning' (TEL), which questions how the processes of teaching and learning can benefit from the use of technology [4,20]. For instance, in [21], researchers examined laboratory work through Virtual Reality (VR) as a sustainable teaching tool with multiple benefits. The authors suggest that the robotic simulator is a sustainable teaching method, as all students get the opportunity to manage their own version of the robotic cell, without queuing delays and extra costs (which is usually the case with a real robotic arm in a laboratory), and while being safe of damaging the cell components. Moreover, within the framework of TLE, we can also locate the so-called smart sustainable education; that is, learning supported by a variety of tech-enabled smart devices, such as smartphones and tablets [22]. Learning platforms (also known as Virtual Learning Environments, VLE), Learning Analytics (LA), Open-Source Software (OS), and computational tools (such as Google-Duo, Hangout, and previously Google Plus), forge sustainable teamwork evaluation—subject to teamwork and certain infrastructure interconnections [18].

In this article, our emphasis is on the potentially sustainable nature of multidisciplinary and multicultural teamwork, where members engage with real-case tasks and with the support of technology (Google Applications). It is widely documented in the literature that multidisciplinary and multicultural group collaboration helps students gain deeper knowledge, share experiences, and achieve common tasks [5,23-27]. Students are likely to produce innovative ideas, stemming from various viewpoints, experiences, and cultures [5,28-31]; and deal with real-world situations, which require multi-disciplinary intellectual capital [5]. This process could be sustainable education as it improves students' awareness, critical thinking, and skills to deal with an issue in the real world. However, multidisciplinary and multicultural collaboration is not without its challenges [32]. Time management and difficulties arising from people with different backgrounds are common [31]. In addition, while diversity can increase creativity and innovation [33,34], it often leads to conflict. These kinds of weaknesses are the subjects of study in this article.

Moreover, along with multidisciplinary and multicultural teamwork, the current article introduces another two dimensions, which can be linked to sustainable teaching. Case-based Learning (CBL) and Problem-based Learning (PBL) are among the most common student-centered methods that provide examples of real-life/corporate cases. They are based on the same principles: teach content with real-world or authentic situations and expose students to multiple sources of viewpoints. Both learning pedagogies can ensure active participation; lead to innovative solutions to problems; provide students with relevant opportunities to link theory with practice; and engage students in a collaborative environment [5,9]. The question is, how sustainable is the implementation and outcome of these practices in a multicultural and multidisciplinary cohort? To our knowledge, the current article is the first study exploring MMT through CBL and PBL in the sustainable education framework.

The quest of sustainable teaching practices is a living process $[4,13]$. Practices are tested, scrutinized, and informed further for application in different contexts, diversified backgrounds, and in the light of continuous technological change. In pursuit of sustainable teaching, no practice is standalone or complete. Therefore, we revisit teamwork and explore the sustainability of MMT through CBL and PBL, in the light of wider technological advancements-in education (e.g., [35-38]) as well as the wider society and industry (e.g., [39-42]). 


\section{Research Design and Methods}

\subsection{The Context}

Multidisciplinary and Multicultural Teamwork through Case-based Learning and Problem-based Learning was applied in the 'Management of Innovation and Technology' course. The undergraduate module of 'Management of Innovation and Technology', which is central to our discussion in the current study, is an international cohort with similar characteristics. It is an interdisciplinary module, offered as an elective to 3rd- and 4th-year Business School and Computer Science students, and a required/elective for Erasmus students from diverse disciplines and cultures. As presented in the 'Findings' section, the cohort is comprised of students from at least 13 different countries. The aim of the course is to survey the field of technology and strategy for managers and entrepreneurs. It provides students with the essential tools, techniques, and viewpoints for productive thinking and formulation of technology strategy. Among a range of useful learning activities (e.g., faculty and guest lectures, seminars, and guided reading of case studies), the course includes inclass teamwork exercises, student interaction through Google Duo and Google Hangout, as well as student-led presentations on real-problem situations.

The application of Multidisciplinary and Multicultural Teamwork through Case-based Learning and Problem-based Learning is aimed at challenging student teams to work together on common projects and to expose them to technology innovation management applications [28,41]. During the second week of the semester, the lecturer formed student groups comprising four to five students each, coming from different disciplines and countries. Throughout students' problem-based and case-based teamwork, the lecturer was acting as a facilitator. Students' active participation and contributions in group discussions were of major importance for the overall grading assessment, measured by a rubric on students' arguments, answers, presentations, and participation in teamwork discussions.

The groups had to solve either real-life cases or problems. The lecturer used cases from the Harvard School of Business Publishing Case Center [42]. As presented in Table 1 , most of the cases used were in the field of technology, innovation, patents, copyrights, intellectual property rights, and corporate strategy—reflecting the module's content.

Table 1. Sample list of the case-studies used for MMT through CBL and PBL.

\begin{tabular}{l}
\hline $\begin{array}{l}\text { 'Goldieblox: Toy Company and Copyright Infringement'. Case referring to GoldieBlox } \\
\text { being accused of copyright violation. }\end{array}$ \\
\hline $2 \quad \begin{array}{l}\text { 'Fight for a Patent Vs Keeping your Invention a Trade Secret'. Case referring to Wyeth } \\
\text { pharmaceutical that relies on patent and trade secret protection for its innovation. }\end{array}$ \\
\hline $3 \quad$ 'The CEO of Novartis on Growing After a Patent Cliff'. Case describing the challenges with \\
Diovan, a patented drug accounting for 20\% of the pharmaceutical division's revenue. \\
'The growth of Electric Vehicles Industry: Facilitating and Imputing Forces'. Case analyzing \\
the forces driving the 21st century automotive industry toward electrification. \\
Source: Harvard Business Review [42]. \\
The problems given to students varied according to each lesson's weekly learning \\
objectives. For instance, an in-class problem asked the groups to think about a situation in \\
which their organization needs to (a) introduce an innovation that will contribute to the \\
organization's growth; (b) evaluate alternative innovations suggested by team members \\
and decide which one will be more appealing to customers; (c) come up with a strategic \\
plan that is more appropriate to implement in order to benefit from innovation; and (d) \\
decide how to accomplish a competitive advantage. Much of the teamwork and preparation \\
had to take place online through Google applications, such as Google Duo and Google \\
Video Talk.
\end{tabular}

\subsection{Methods}

To investigate the effectiveness of MMT through CBL and PBL in terms of sustainability, a mixed-method approach was used, combining qualitative and quantitative methods. 
The methods used included direct observation, questionnaire distribution and focus group interviews.

Details about the rationale of the choice of these methods and how they were employed are presented below.

\subsubsection{Physical and Virtual Direct Observation}

The first method employed by this study is 'Direct Observation', also called an 'Observational Study' [43]. Direct Observation is often used for qualitative research about natural phenomena, human or animal behavior, operation of machines [44], cultures, events, and other situations [43]. This method was initially used by anthropologists and later adopted by various other disciplines including, but not limited to, psychology, sociology, education [45], marketing [46], and linguistics. Direct observation is used alone or combined with other methodological approaches. In the current study, the process included the lecturer observing the students closely and discreetly during group work, both in a physical classroom and Google applications, such as the Google Duo and Hangout tools.

The decision to conduct direct observations concerns a researcher's ability to observe students' behavior and collect findings while students interact during teamwork. Other than student behavior, the process facilitated collection of findings regarding the effectiveness of MMT through CBL and PBL in-class activities. The lecturer also maintained a digital journal about students' interaction and engagement on Google Duo and Google Hangout. The observation process lasted for 12 weeks during the Fall of 2019. To examine the data elicited from the observation process, a qualitative (content) analysis was employed.

\subsubsection{Online Questionnaire}

In addition to the observation sessions, it was deemed necessary to obtain data reflecting students' perceptions and views on the MMT experience. A questionnaire was designed in Google Forms and was distributed online in late January 2020, after the completion of the course and submission of grades. Participants had fifteen days to respond. At this point, it is important to note that the accounts of all previous class members remain active on the cloud as part of a vibrant online community. Students and graduates may continue to communicate and exchange ideas, amongst them and with the lecturer, even after the completion of the course. Friendships and professional collaborations are formed by students at the international level, whereas the lecturer often adopts a mentoring role. This practice, which is a form of sustainable education, made the recruitment of questionnaire participants easier. Fifty-nine (59) individuals answered the questionnaire in total. The results were calculated by the same software that generated the forms.

The questionnaire was clear, concise, and easy to answer. It comprised four questions on demographics to obtain information about the participants' age group, gender, country of origin, and major of study. Twelve statements followed asking students their opinion about teamwork, their work on case studies and problems, and learning in a multidisciplinary and multicultural environment. Learners were asked to evaluate the MMT experience through CBL and PBL activities. For this purpose, they had to select one answer among four choices (Strongly Agree, Agree, Disagree, and Strongly Disagree). The actual statements appear in Table 2 below.

It is worth mentioning that, to ensure the wording was clear and appropriate, the questionnaire was first administered to ten volunteers on a pilot basis and adjustments were made following feedback. 
Table 2. Survey statements on MMT CBL and PBL.

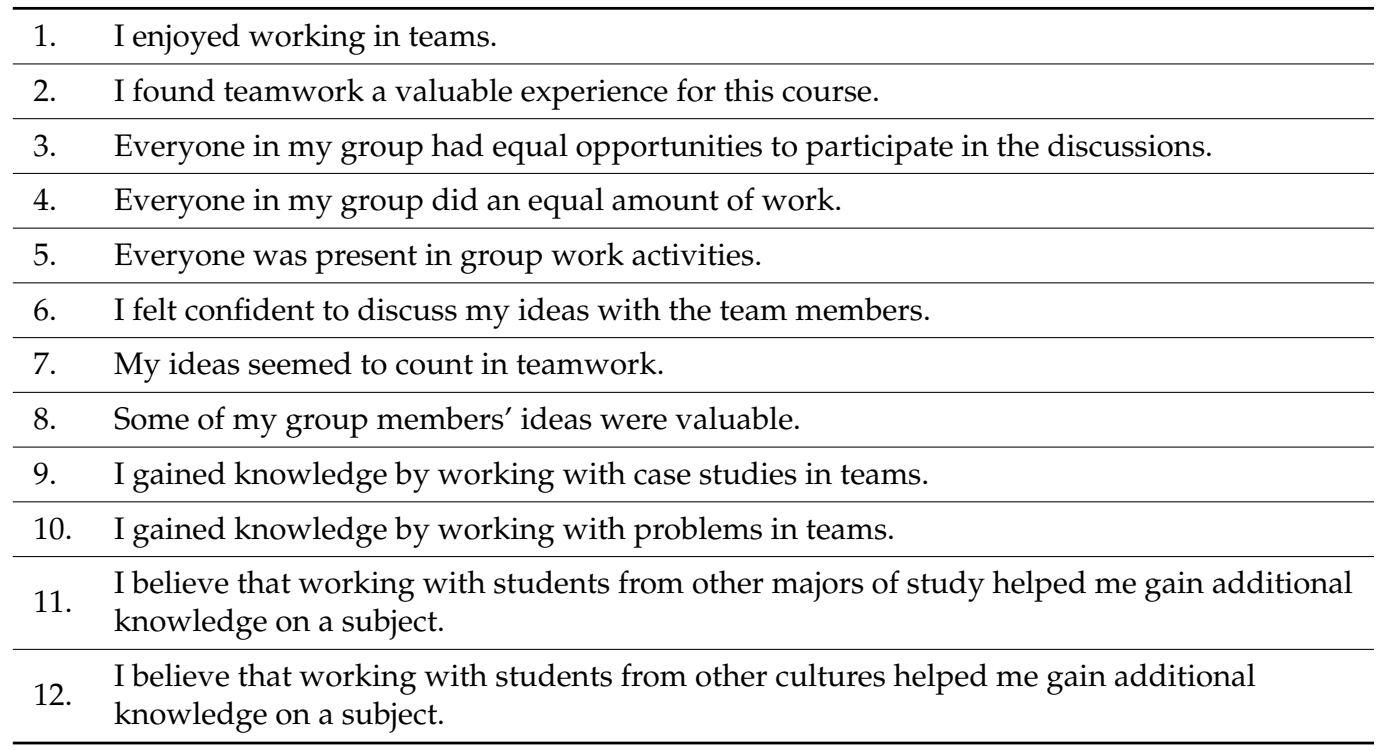

\subsubsection{Focus Groups}

After the completion and analysis of the questionnaire, two focus-group interviews were also conducted. The use of focus groups was deemed useful as it was felt by the authors that they would add to the understanding of key aspects of the research that could not be adequately addressed in questionnaire-format questions. In the focus-group interviews, open-type questions asked the participants to reflect on their experiences working in multicultural and multidisciplinary teams. These included questions relating to whether and how 21st century skills were enhanced in the class; how the use of technology assisted or hindered the work done; whether self-assessment or peer assessment took place; if there were any challenges/difficulties in the process; whether the students felt that training could have been provided before working in such teams; and what kind of training this could have been.

Two focus groups were organized-one with existing students of the class and one with ex-students. In the first group, eight participants took part and in the second one, six. The focus groups were administered online during the COVID-19 pandemic period, as with most of the university's operations [2]. The participants were very comfortable with the use of technology; thus, this mode of communication was not an obstacle to expressing their views. The first focus group lasted for $85 \mathrm{~min}$ and the second for $90 \mathrm{~min}$.

\section{Findings and Discussion}

\subsection{Observation}

- Sustainability through Knowledge Transfer and Sharing

Findings reveal that, in all MMT through CBL and PBL activities, the greatest benefit was knowledge transfer from one MMT member to another. There was knowledge sharing emerging from the students' disciplines, and knowledge stemming from their cultural backgrounds. Thus, two types of Knowledge Transfer are identified in this type of teamwork: (a) Multidisciplinary Knowledge Transfer and Sharing; and (b) Multicultural Knowledge Transfer and Sharing. When it comes to Multidisciplinary Knowledge Transfer and Sharing, the following observation note about MMT through CBL is indicative (as presented recently in a conference paper, see [5]):

"Two cases were assigned to student teams to read and analyze regarding pharmaceutical industries' intellectual property rights: (a) The Wyeth's Case patent and trade secret protection for its innovation where different forms of intellectual property rights are used to protect valuable information; (b) The CEO of Novartis 
Case with the company facing a big challenge with Diovan, so that the company avoids losing its patent. It was interesting to see that the three ERASMUS students with major of study in Healthcare Management shared their experiences with the pharmaceutical procedures for medication and the continuous fights to achieve competitive advantage and be the First Mover". [5]

The following note is also representative of MMT effectiveness through CBL:

"Students were given a case on Goldieblox toy company and Copyright infringement. One student from Lithuania studying Computer Science shared her personal professional experience in writing the code for a software that she plans to sell. While discussing the case of Goldieblox toy company, she explained the importance of copyrights on music and software production and how she plans to copyright her new software to deter imitation". (also presented in [5])

As seen from the above two excerpts from the lecturer's observations, students have shared with their team members information drawn from their disciplines. Much of this knowledge concerns prior professional experiences. During the process, team members of other disciplines have become aware of issues unknown to them and have gained interdisciplinary knowledge. This ties in with $[23,24]$ that multidisciplinary collaboration among team members can reinforce each other and enhance collective effort toward the achievement of common goals.

In addition to the significance of multidisciplinary teamwork, the following observation note reveals the significance of multicultural group work on Case-based and Problembased Learning activities (as presented recently in a conference paper, see [5]):

"This case gave students data on the electric vehicle industry, starting with the history of the electric car and then moving on to the forces driving the twenty-first century automotive industry toward electrification. Students from Cyprus, Libya, and Egypt stated that they would not buy an electric car since their countries do not support the infrastructure for such Technology innovation and the government does not offer any incentives to motivate them. Students from Germany said that grants for plug-in hybrids are 4500 euros. For vehicles priced over 40,000 euros the grants will rise to 5000 euros. They said that the German government wants to have 10 million electric vehicles on the roads by 2030. A student from The Netherlands living in Finland mentioned that in The Netherlands, with the government approval starting in 2030, only emissions free vehicles will be allowed to be newly registered. The incentives are:

- funded subsidization for the purchase of electric cars valued at 6000 euros, beginning in 2021.

- VAT freed electric vehicles and motor vehicle taxes starting in 2025" [5].

Another observation note illuminating the effectiveness of MMT is the following,

"Students were given real life cases on how Pharmaceutical Industries protected their inventions. It was obvious that students from Germany, The Netherlands, Lithuania, and China were familiar with such issues; while students from Bulgaria and Cyprus stated that they had no idea how important it was for such industries to protect their innovations and capture the value from their products."

These examples show that students have transferred and shared their own national and cultural experiences with others, thus informing their team members about values and policies that exist at the international level. Internationalization in education is according to Giddens (1999) a positive response to globalization, which stimulates nations to interact and enrich each other with fresh cultural insights and exchanges [47].

The following notes concern Problem-based Learning activities, which reveal knowledge transfer in a way similar to Case-based Learning:

Problem A: 
"All nine groups have been assigned to come up with a Technology innovation. After $11 / 2 \mathrm{~h}$ of discussion on various aspects of the innovations, students decided to keep three out of nine and finally ended up with one, The Invisible Solar Panels-ISP. This idea has been proposed by a Cypriot student in his final year of Management studies. He managed to convince his classmates that technological development of photovoltaic systems moves in a fast pace. He explained that although Cyprus is blessed with sunshine and is an excellent place to utilize solar energy, it has limited production of solar energy. The student from Egypt and another Cypriot student agreed."

Problem B:

"The students were asked to find ways to capture value from innovations, achieve competitive advantage, establish a brand value and do proper promotion. One student with Marketing background explained to her teammates how a marketeer thinks and which strategies to follow in order to reach the majority of early and late adopters of photovoltaic systems. Students argued that they were completely unfamiliar with some of the strategies she suggested to them even though they had taken Marketing courses. They all agreed that one needs to think like a marketeer". (as presented in a conference paper, see [5])

The above observations are a few among several PBL examples, where Multidisciplinary Knowledge Transfer and Sharing and Multicultural Knowledge Transfer and Sharing, are proved helpful during MMT. In addition, no student complaints were recorded regarding the use of Google applications. As mentioned earlier (in the Methods section), the accounts of all previous cohorts for this module remain active on the cloud as part of a vibrant online community. Students and graduates can continue to communicate, discuss, and exchange ideas amongst them and with the lecturer, for as long as they wish. Students seem to find the interaction via online applications helpful.

Overall, the observation findings confirm that students with different specializations and cultures working in teams enhance a simultaneous knowledge transfer and information sharing on topics related to their field and cultural experiences. As Gassmann [31] and Adler [32] support, team members' diverse values and cultural experiences can increase creativity and innovation. Through MMT collaboration, students can gain a better understanding of a subject from the point of view of diverse fields of study and cultures; exchange knowledge with the other team members; gain interdisciplinary and intercultural skills; and develop critical thinking and problem-solving competencies.

By observing students' discussions, it was noticed that diversity in their major of study and cultural background has contributed significantly in seeking solutions to problems and challenges by sharing their existing knowledge and skills. Although to our knowledge there are currently no studies discussing multidisciplinary and multicultural teamwork as a sustainable teaching practice, the process we have observed, along with the discussion of students' real-life experiences, seem to align with the principles of sustainable educationespecially in terms of its international orientation and 21st century skills. However, as explained in the next section, there were also several challenges, which have influenced the students' performance.

\subsection{Challenges: Punctuality, Commitment, Learning Styles, and Language Barriers}

In her observation notes, the lecturer refers to evident challenges regarding the implementation of MMT through CBL and PBL activities. A notable challenge concerned language barriers as peers were facing communication difficulties, both face-to-face and on Google applications. The following quote from the lecturer's notes is indicative:

"Some students found the cases difficult to read and faced difficulties to communicate with the others due to language difficulties. The ones more competent in English language had to rephrase their arguments in order to explain what they 
meant. Although discussions took longer, they figured out ways to collaborate and come up with innovative ideas and solutions."

This finding resonates with previous accounts, suggesting that international students are faced with insecurity and uncertainty in diversified and multi-cultural learning cohorts [48]. However, interestingly enough, despite the language barriers, what is prominent here is that through MMT, the students who were more proficient in the English language collaborated with the ones facing language difficulties by adjusting their communication styles in order to help them understand the point of discussion. Thus, the team members improved three components of their intercultural competence, which according to [49] is the improvement of communication, interaction styles, and flexibility in resolving communication misunderstandings. It also seems that there was an attempt by some students to develop an inclusive environment for all team members. This is revealing of how a difficult process may strengthen teamwork interaction, make students more considerate, and equip them with skills (e.g., problem-solving and negotiation skills) for a career at a global level. In this sense, we may claim that despite the obstacles, MMT through CBL and PBL is a sustainable teaching practice.

However, we should not dismiss or undermine the challenges of the process. On the contrary, some of the difficulties persisted throughout the semester. Table 3 presents several of the main obstacles identified through the observation process.

Table 3. Ten of the most common obstacles identified during MMT through CBL and PBL.

\begin{tabular}{ll}
\hline 1 & Lack of punctuality at teamwork meetings \\
\hline 2 & Lack of commitment to teamwork tasks \\
\hline 3 & Language barriers \\
\hline 4 & Different working and learning styles \\
\hline 5 & Interpersonal difficulties/preference to work solo 'attitudes' \\
\hline 6 & $\begin{array}{l}\text { Difficulty to stick to the teamwork's ground rules (e.g., power-off mobile phones during } \\
\text { meetings) }\end{array}$ \\
\hline 7 & Arrive late or fail to show up for the team presentation \\
\hline 9 & Different communication styles/preferences-physical vs. digital \\
\hline 10 & $\begin{array}{l}\text { Poor team culture: difficulty of some members to identify with the group } \\
\text { teamwork process }\end{array}$ \\
\hline
\end{tabular}

Source: Lecturer's observation journal.

Some students were not punctual on their arrival. Others were not showing up at all, putting the burden on the remaining team members. Some students used to arrive unprepared or refused to follow the team's workflow. Some differences in working and learning styles also resulted in misunderstandings and unproductive conflicts, which influenced the teams' decision-making process. Most importantly, some students failed to show up on the day of the team presentation. At the end of the course, some of these difficulties resulted in lower student performance, raising doubts about the sustainability of implementing MMT through CBL and PBL. Moreover, as we present below, an attempt has been made to triangulate the observation findings through a student questionnaire.

\subsection{Students' Questionnaire}

\subsubsection{Demographics}

The total number of completed questionnaires was 59 . The majority were between the ages of 18 and 24 (47 or 79.7\%), whereas 11 (18.6\%) were between 25 and 34 and $1(1.7 \%)$ above 35 (Figure 1). 


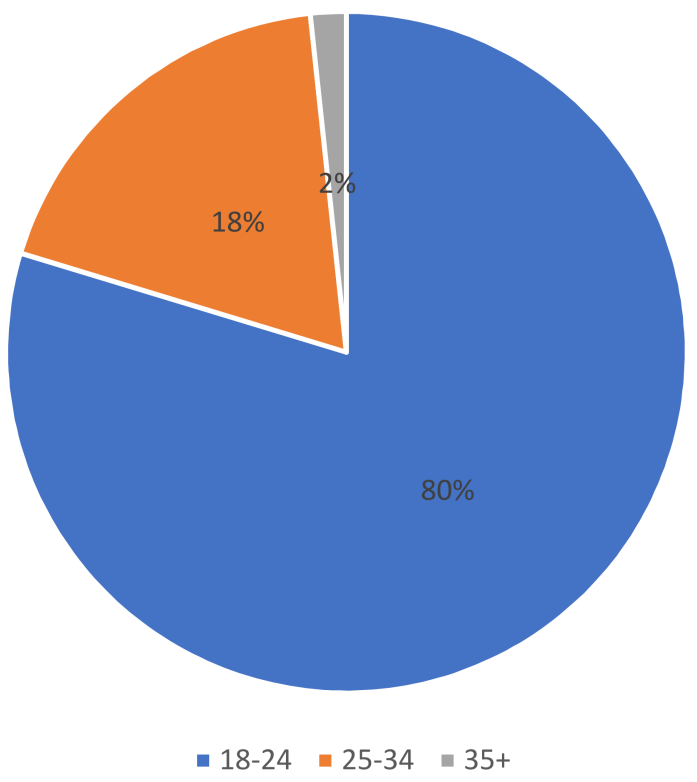

Figure 1. Age of the respondents.

Thirty-one (31) or 52.5\% were females whereas 28 (47.5\%) were males (Figure 2).

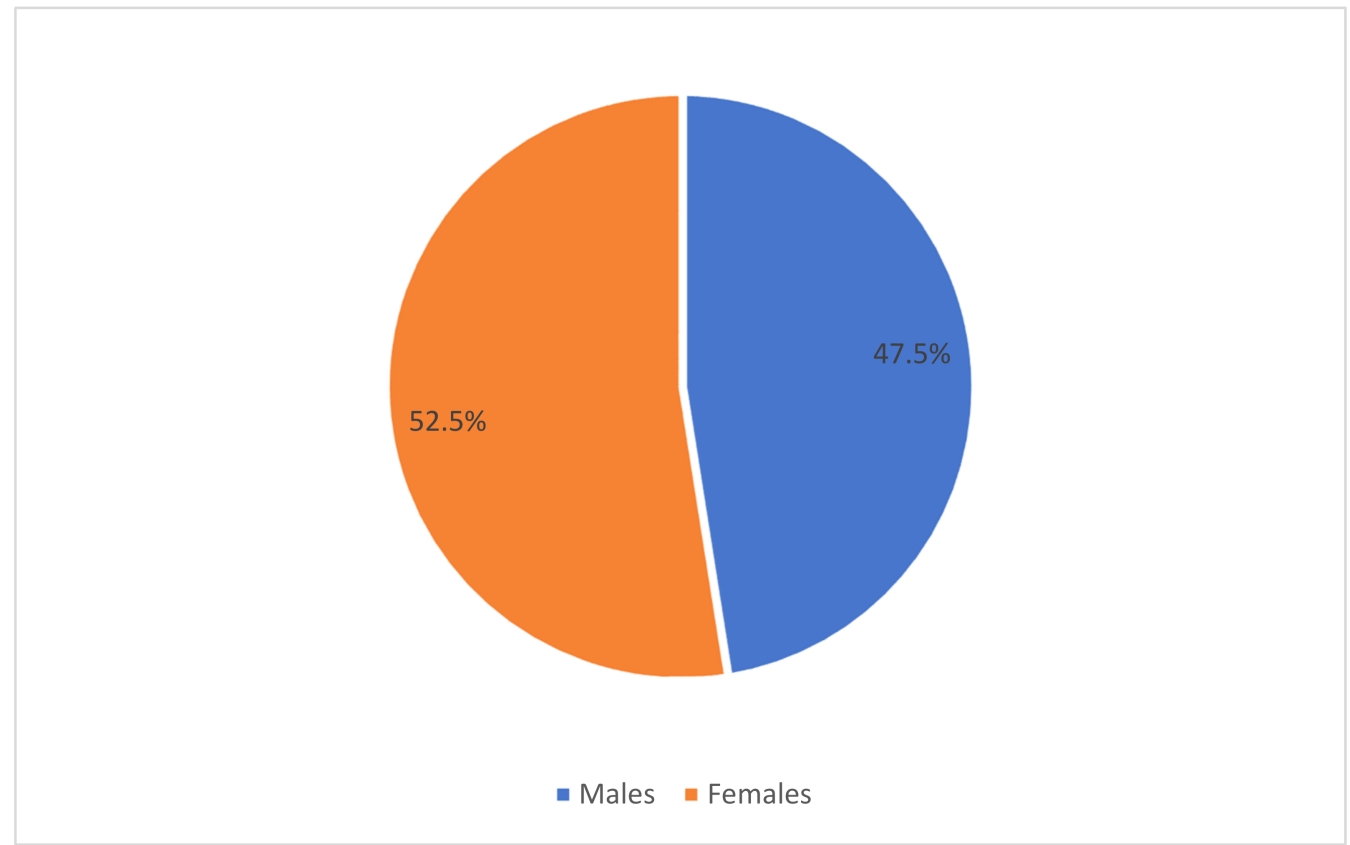

Figure 2. Gender of the respondents.

Twenty-two (22 or $37.3 \%)$ were Cypriots, 6 (10.2\%) were Russian, $5(8.5 \%)$ were from Greece, and $26(44.0 \%)$ other nationalities from 10 different countries. Figure 3 presents the main nationalities of the sample and Table 4 the sample's nationality mix in alphabetical order. 


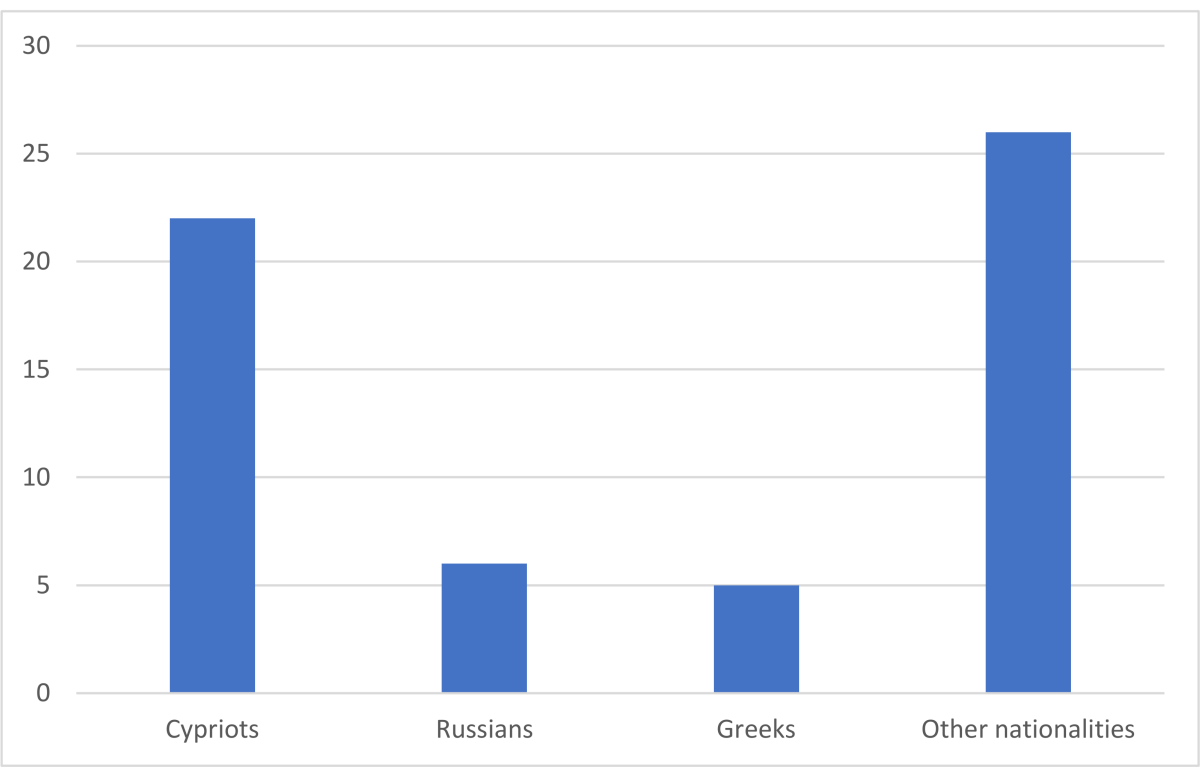

Figure 3. Respondents' nationality.

Table 4. Sample's nationality mix in alphabetical order.

\begin{tabular}{llll}
\hline 1 & Austria & 8 & Greece \\
\hline 2 & Bulgaria & 9 & Latvia \\
\hline 3 & China & 10 & Libya \\
\hline 4 & Cyprus & 11 & Lithuania \\
\hline 5 & Egypt & 12 & Romania \\
\hline 6 & Finland & 13 & Russia \\
\hline 7 & Germany & & \\
\hline
\end{tabular}

Seventeen (17) students or 29.3\% were Management Information Systems majors, 8 students $(13.8 \%)$ were studying Business Administration with a concentration in Management, 7 or $12.1 \%$ were Business Administration students with a concentration in Marketing, and 5 students or $8.6 \%$ were Business Administration students with a concentration in Economics and Finance. The rest of the respondents (22 or 37.3\%) studied other courses in smaller numbers (Figure 4).

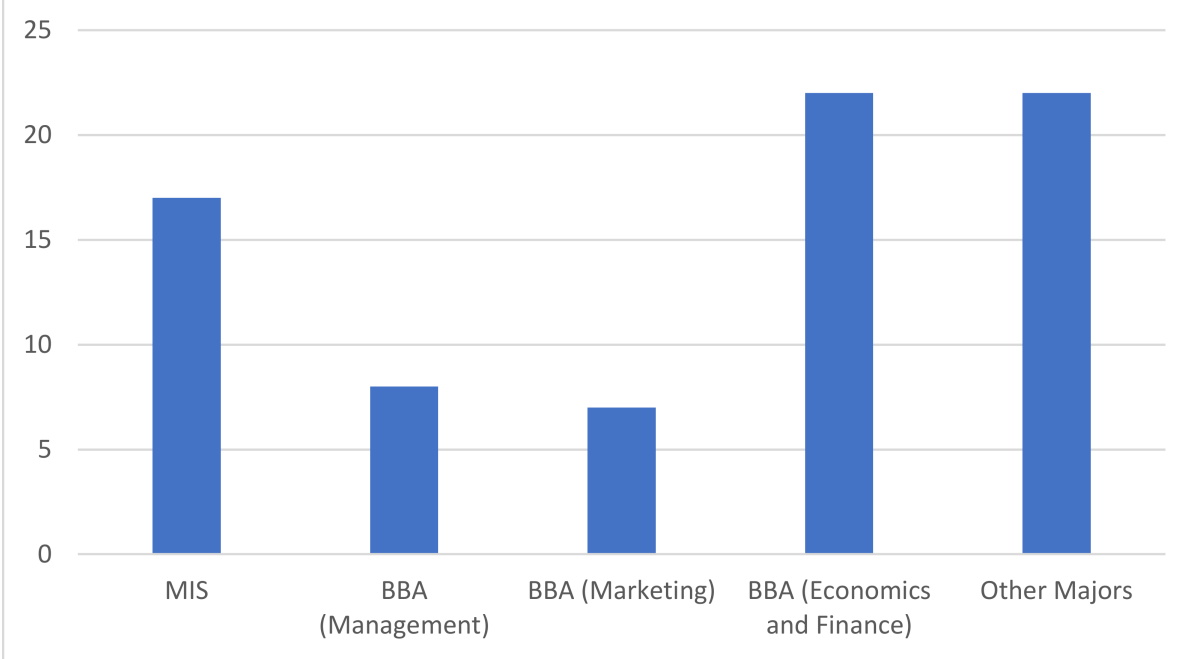

Figure 4. Respondents' major of study. 


\subsubsection{Students' Perceptions about MMT, CBL, and PBL}

A significant majority (46 out of 59 respondents or $78 \%$ ) indicated that they enjoyed working in teams (Statement 1 ). More specifically, 17 students or $28.8 \%$ strongly agreed and 29 or $49.2 \%$ agreed. Regarding Statement 2, "I found teamwork a valuable experience for this course", almost all respondents (58 out of 59) found teamwork a valuable experience for the course ( 24 students or $40.9 \%$ strongly agreed and 34 or $57.6 \%$ agreed, as presented in Figure 5).

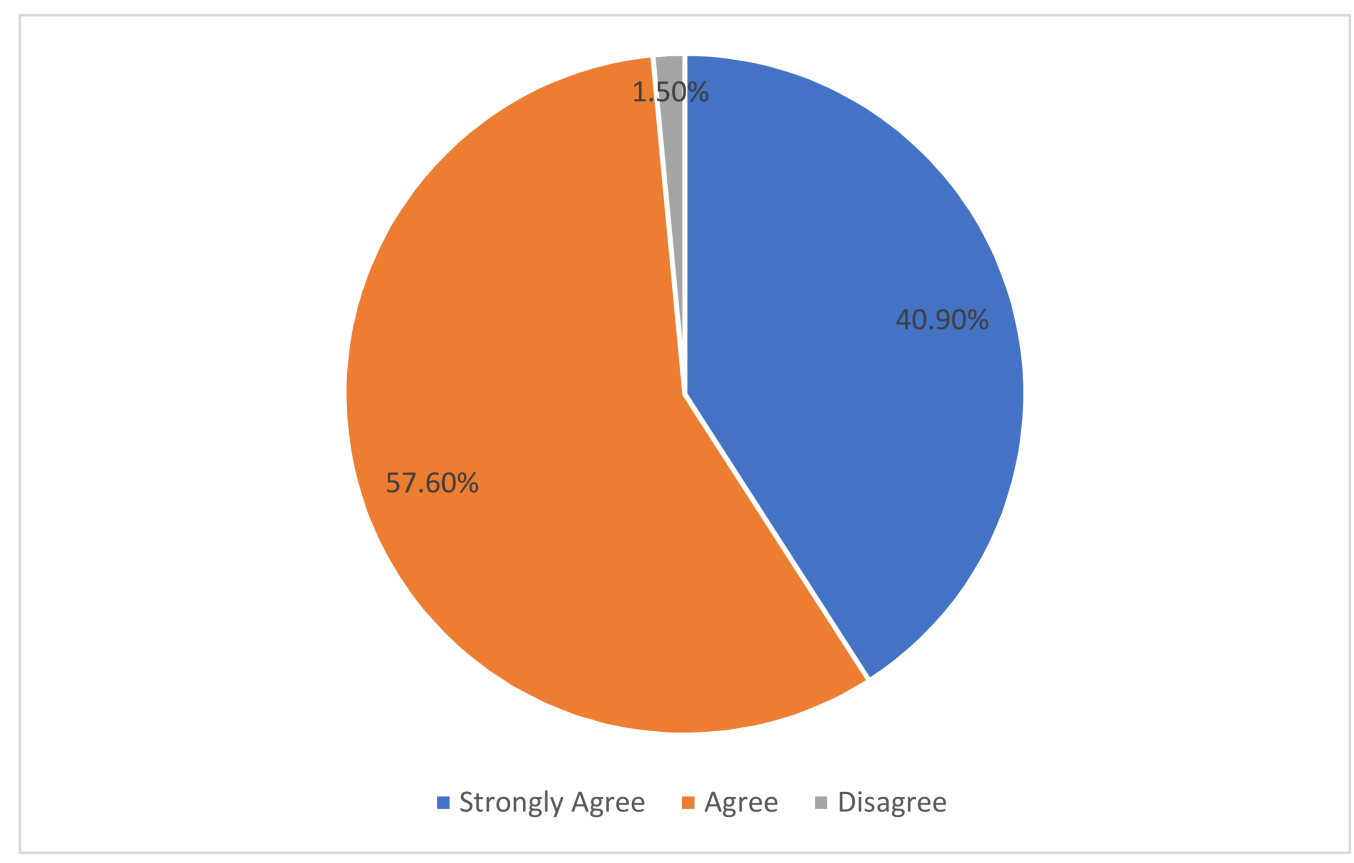

Figure 5. Statement-I found teamwork a valuable experience for this course.

Comparing the results of the first statement with the observational findings, we reconfirm that most students enjoyed working in teams. Despite the challenges, it was prevalent that the engagement and interaction among the team members were appreciated by most. These findings are consonant with previous studies on student engagement [16]. At the same time, both sets of findings reconfirm that for some students $(22 \%)$, MMT through problem solving is not their preferred style of learning. However, compared to the observation's findings, the results of the second statement point to a paradox. On the one hand, 58 out of 59 responded that they found teamwork a valuable experience. On the other hand, many students' behavior and actions during observations were diametrically opposed (e.g., as presented in Table 3, students requesting to prepare and deliver their presentations individually).

Moreover, the discomfort experienced by some students about teamwork (as this was documented through the observation sessions) has also emerged through survey statements 3, 4, and 5 (depicted in Table 2). The group of respondents were asked to respond to Statement 3, "Everyone in my group had equal opportunities to participate in the discussions", and Statement 4, "Everyone in my group did an equal amount of work". A small majority ( $60 \%$ vs. $40 \%$ ) responded positively to the former statement (8 respondents or $13.6 \%$ strongly agreed and 27 or $45.8 \%$ agreed) while $23(39 \%$ ) disagreed and $1(1.7 \%)$ strongly disagreed, whereas a similar majority responded negatively to the latter (5 students or $8.5 \%$ strongly disagreed, 30 or $50.8 \%$ disagreed, 16 or $27.1 \%$ agreed, and 8 or $13.6 \%$ strongly agreed). This discomfort is reflected clearly in Figure 6, raising concerns about the suitability of this practice as a sustainable method. 


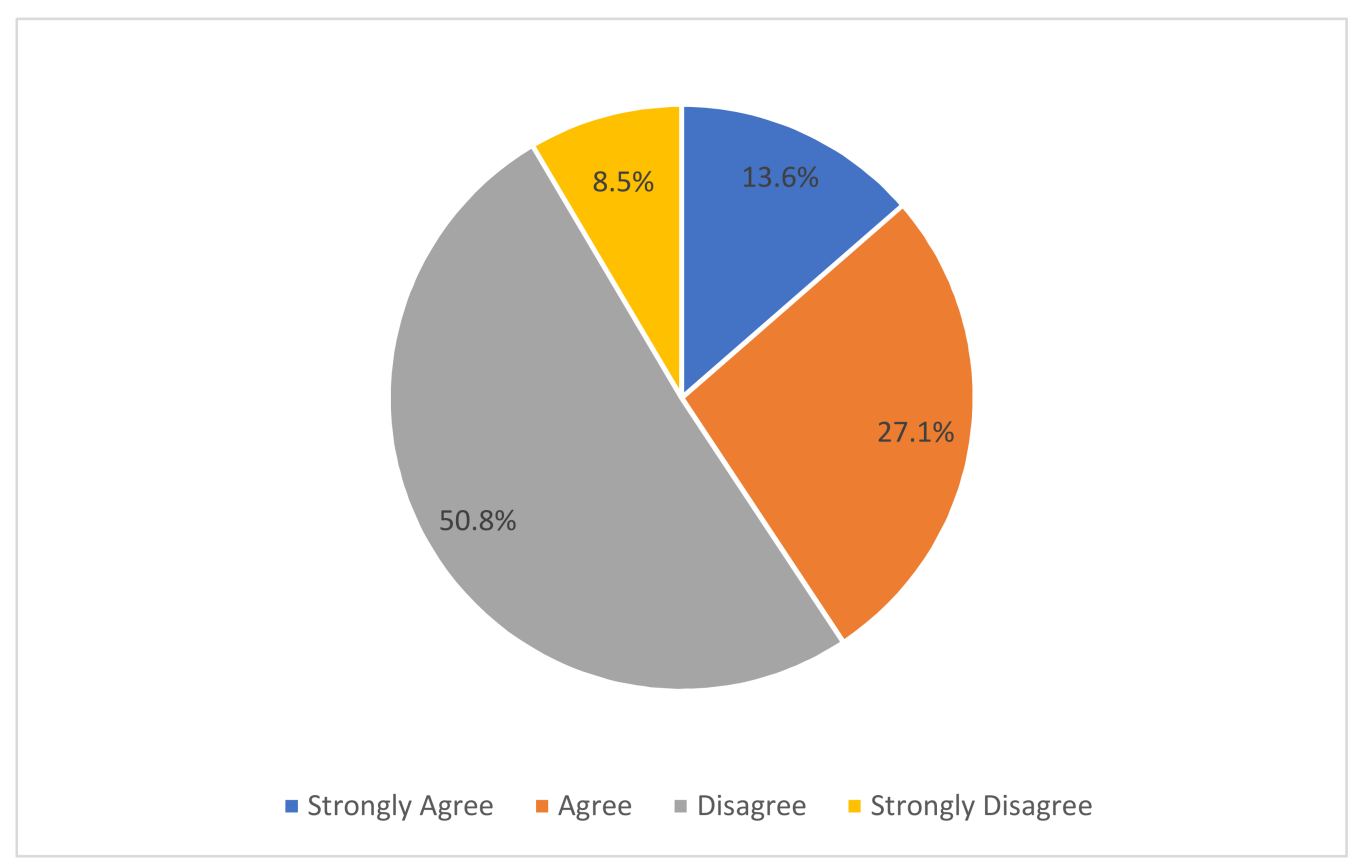

Figure 6. Statement 4-Everyone in my group did an equal amount of work.

Regarding Statement 5, "Everyone was present in group activities", the respondents were approximately equally split (53\% agreed/strongly agreed whereas $47 \%$ disagreed/strongly disagreed, Figure 7). The responses in these three statements resemble the observation findings, especially regarding teamwork challenges, as well as the previous literature [32]. As listed in Table 3, not all members were equally committed to teamwork and tasks; also, not all members were present and/or punctual to team meetings - either physically or on Google sites. These findings can also be linked to different learning styles [30], difficulties to perform teamwork through the learning platform, and increased stress levels (as indicated in Table 3), further raising concerns about the sustainability of MMT through CBL and PBL.

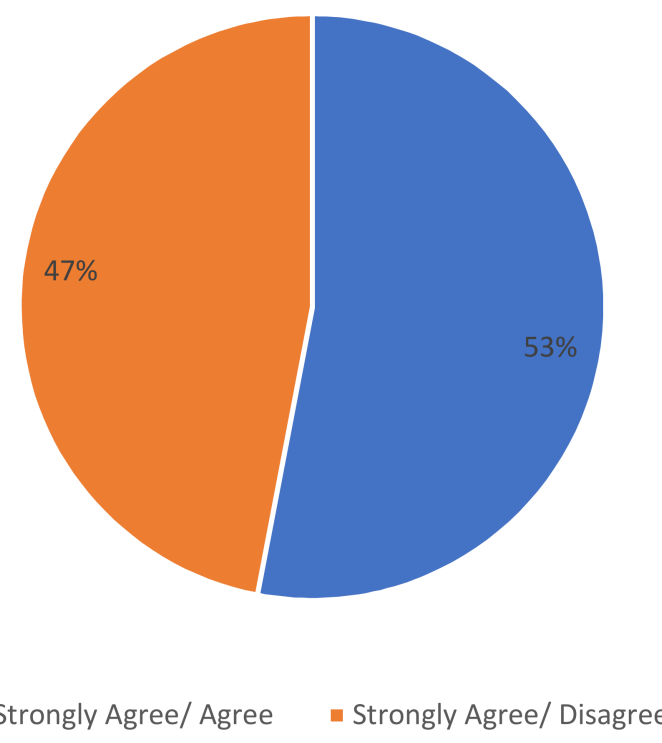

Figure 7. Statement 5-Everyone was present in group activities. 
Moreover, while a significant majority (62.1\% agreed and $17.2 \%$ strongly agreed) felt confident to discuss their ideas with their team members (Statement 6), a large number of students (about $20 \%$ ) were reluctant to discuss certain aspects. A number of students insisted on avoiding a discussion on topics that are considered taboo at home (such as a discussion on how personal data are used).

A majority of students (18.6\% strongly agreed, $59.3 \%$ agreed) believed that their ideas seemed to count in teamwork (Statement 7). For Statement 8, a noteworthy majority ( $23.7 \%$ strongly agreed, $50.8 \%$ agreed) found some of their group members' ideas valuable. Significant majorities also believed that they gained knowledge by working with case studies and problems in teams. More specifically, $86 \%$ agreed (28.8\% strongly agreed, $57.6 \%$ agreed) with Statement 9, "I gained knowledge by working with case studies in teams", and $90 \%$ (39\% strongly agreed, 51\% agreed) with Statement 10, "I gained knowledge by working with problems in teams". Finally, a majority of the respondents believed that working with students from other majors of study and other cultures helped them gain additional knowledge on a subject. More specifically, for Statement 11, "I believe that working with students from other majors of study helped me gain additional knowledge on a subject", $30.5 \%$ strongly agreed and $62.7 \%$ agreed, with only $6.8 \%$ disagreeing, as indicated in Figure 8.

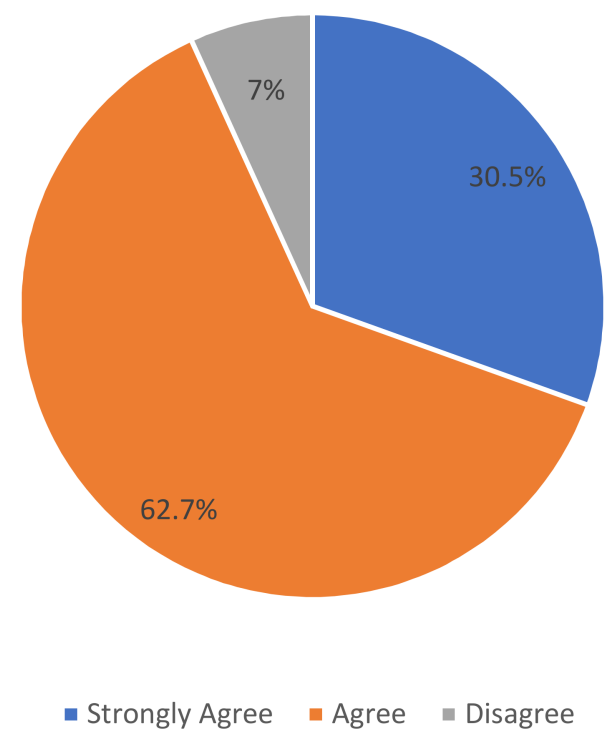

Figure 8. Statement 11-I believe that working with students from other majors of study helped me gain additional knowledge on a subject.

Similarly, for Statement 12, "I believe that working with students from other cultures helped me gain additional knowledge on a subject", $42.4 \%$ strongly agreed and $45.8 \%$ agreed, with only $11.9 \%$ disagreeing (Figure 9). 


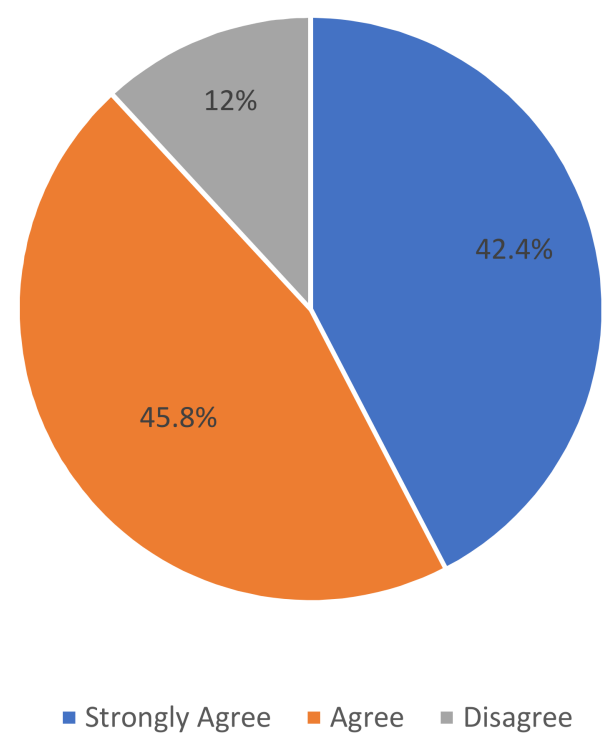

Figure 9. Statement 12-I believe that working with students from other cultures helped me gain additional knowledge on a subject.

\subsection{Focus Groups}

\subsubsection{1st Century Skills}

The first question posed to the invited focus-group participants was to consider which of the 21st century skills were enhanced, according to their opinion, and in what way. Twelve skills were mentioned, as shown on the Table 5 below.

Table 5. 21st century skills.

\begin{tabular}{ll}
\hline & Skill \\
\hline 1 & Critical Thinking and Problem Solving \\
\hline 2 & Creativity and Innovation \\
\hline 3 & Communication \\
\hline 5 & Collaboration \\
\hline 6 & Information Literacy \\
\hline 7 & Media Literacy \\
\hline 9 & ICT Literacy \\
\hline 10 & Flexibility and Adaptability \\
\hline 11 & Initiative and Self-Direction \\
\hline 12 & Social and Cross-Cultural Skills \\
\hline Source & Productivity and Accountability \\
\hline
\end{tabular}

Source: https:/ / www.aeseducation.com/blog/what-are-21st-century-skills, Accessed 23 June 2020 and [5].

Critical thinking and problem solving was a skill that participants felt was enhanced by the experience in MMT. This was done, according to the participants, by the work on cases/problems that had to be completed. This work required considering different options, thinking critically about proposed solutions, and, eventually, providing a solution to the problem. All these activities contributed to the enhancement of this critical thinking and problem solving. 
Creativity and innovation were also another skill that was enhanced, according to the participants. The analysis of cases or solutions to problems involved, invariably, a need to come up with an innovative solution. The participants mentioned a number of examples that required the proposal of innovative solutions. In addition, there was agreement that communication and collaboration were also enhanced by the work in MMT. According to one participant, "it was inevitable that this (i.e., collaboration and communication) would happen given the multidisciplinary and multicultural nature of the teams". Another participant mentioned that the fact that they had to solve a problem together developed their collaboration skills.

Participants did not seem very certain initially as to whether information literacy was enhanced. When it was noted that information literacy can mean understanding facts, figures, statistics, and data, the majority of participants acknowledged that this was enhanced to some extent by reading and discussing cases, some of which included data and figures. Even though one participant mentioned some discussions on how information is published on Facebook, which could contribute towards media literacy, the prevailing view was the opposite. ICT literacy was enhanced, according to participants, mainly by the use of cloud computing.

Flexibility and adaptability were needed, according to students, in interactions with other group members, and this could have a positive effect on this skill. One participant mentioned the different time perceptions she noticed when collaborating with group members coming from other cultures, something that made her more flexible. Another student mentioned the different communication styles in group members, something that had to be accommodated. Overall, this was a skill that was enhanced quite significantly according to participants.

The focus groups' participants were divided in their views as to whether initiative and self-direction were enhanced in MMT work. Some noted that initiative had to be taken when discussing tasks, whereas some others noted that the nature of the teamwork did not encourage all group members to take initiative or be self-directed. In relation to social and cross-cultural skills, participants agreed that these were enhanced by the interaction with other group members. In particular, the diversity of cultural backgrounds was mentioned, which resulted in learning about other cultures and making an effort to collaborate with students of diverse backgrounds.

Productivity and accountability were enhanced according to participants because groups had to deliver work on time and, because of the relatively small number of group members, each one was accountable. Finally, in relation to leadership and responsibility, participants noted the practice of rotating leaders in groups, which gave the opportunity to group members to experience the leadership position and the responsibility it brings with it.

Overall, it was felt by participants that several 21st century skills were enhanced, especially Critical Thinking and Problem Solving; Creativity and Innovation; Flexibility and Adaptability; and Social and Cross-Cultural Skills.

\subsubsection{Technology}

The second focus group question was related to how technology influenced the learning experience and if there were challenges associated with it. It was mentioned that the use of technology, especially Google applications, was helpful because it facilitated communication among members. Examples that were mentioned included the fact that group members could modify documents, communicate from any device using Google Hangout, and do research online using Google Forms. As one participant mentioned, "we managed to work with my team in pleasant conditions, as if we were all in one class". No challenges or difficulties were mentioned other than the occasional problems with internet connection. 


\subsubsection{Assessment}

Regarding self- and peer assessment, it was noted that self-assessment did not happen directly. Peer assessment did happen, primarily through the rotating leadership practice. The majority of participants found assessing others challenging since it required making comments about other students of their teams in a way that was objective and polite. However, they found the process beneficial, as it pushed them to develop their communication and motivational skills. As one participant noted, "It was the first time I have to play the role of a "superior" and it made me realize that assessing others is not easy at all".

\subsubsection{Training}

The prevailing view was that no training was needed to work in MMT on CBL and PBL. A couple of participants, however, noted that some training could have been helpful. One area could include a brief overview of cultural differences in communication styles and behaviors. Some other respondents replied that this was, in a way, done in other courses. The other area in which some students believed that training could have been provided, was in analyzing case studies. The response from several other students was that some guidance was provided in class and the rest could be learned by doing (i.e., practicing).

In sum, the results elicited through observation and questionnaires provide evidence that MMT through CBL and PBL can both facilitate and hinder sustainable learning. Several findings highlight the significance of MMT through CBL and PBL. On one hand, quite a lot of students seem to have enjoyed the teamwork, found the activity a valuable experience, and believe they have gained knowledge by working with case studies and problems in teams with peers from other disciplines and cultures. On the other hand, some students are being divided in their survey opinions about team members having equal opportunities to participate in discussions, being present in group activities, and having equal amounts of work. These challenges reinforce further the observation findings and raise concerns about the suitability of MMT through CBL and PBL as a sustainable method. Towards this end, we depict in the next section the interpretation of our results on an adapted model of Carroll's Pyramid of Corporate Social responsibility and offer several recommendations aiming at making this practice a more sustainable learning experience.

\section{Interpretation of Results and Recommendations}

To more accurately represent our interpretation of findings based on the five dimensions driving the study, we present below a pyramid, which has been adapted by Carroll's Pyramid of Corporate Social Responsibility. Each level of the pyramid resembles one dimension. The pyramid also presents (in parentheses) the value assigned by students to different activities, as observed in the class (physical and virtual) and expressed through the questionnaires and focus groups. We also use the analogy of Carroll's Pyramid to emphasize the different levels of usefulness and degree of sustainability. At the bottom, students find the specific dimension useful. Our findings also point to the characteristics of sustainability. At the top level, the practice seems to be stretching; its usefulness is uncertain and results in unhealthy amounts of worrying among team members (e.g., Table 3).

To facilitate the sustainable use of MMT through CBL and PBL, we present below several suggestions. The Pyramid is used to assist this process.

\subsection{Suggestion 1: Teamwork Training}

Reflecting on the findings we presented earlier, the Pyramid of Students' Expectations (Figure 10) suggests that students seem to assign high value to multi-disciplinary and multicultural interaction. Moving onto the second level, it seems, that the use of technology in learning activity is also welcomed by students-rather desired. Then, CBL and PBL seem to become a bit more challenging, whereas some students seem to be challenged even more by teamwork responsibilities. The chain of sustainability seems to break when case-based and problem-based activities and student responsibilities are involved. This is not surprising given that students from different educational and cultural backgrounds 
possess different skills and habits, which in turn influence the way they work. Furthermore, although classroom teamwork may be a common, unproblematic activity to many students and instructors, it is not necessarily appreciated and favored by all students. It is not everyone's preferred way of learning.

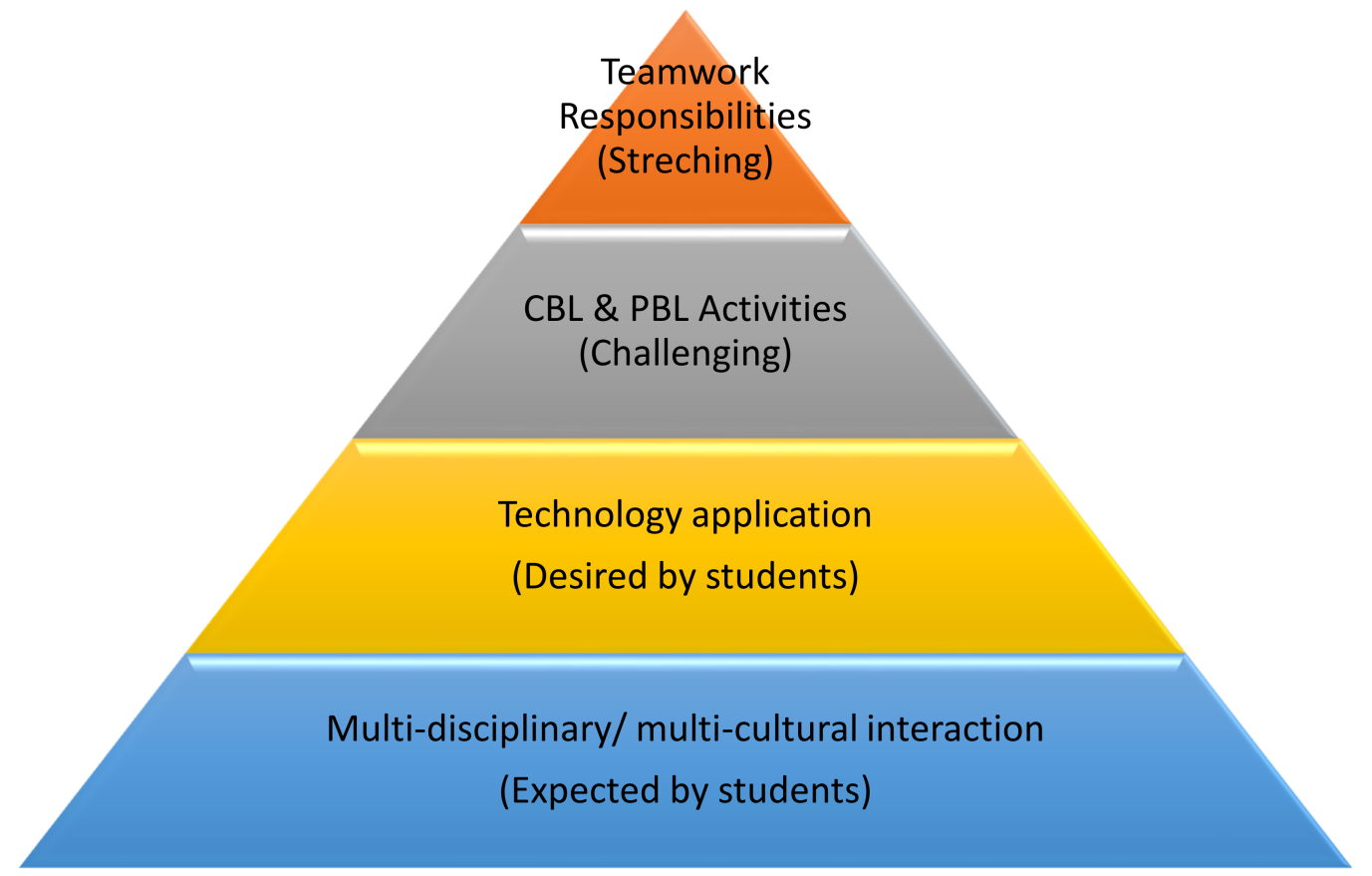

Figure 10. Pyramid of Students Expectations for MMT through CBL and PBL.

Therefore, to improve the sustainability dynamic, our first suggestion concerns 'Teamwork Training'. In other words, teamwork activities need to be mastered in advance. During the first three weeks of the semester, the lecturer may dedicate some time from each lesson to help students comprehend the value of teamwork, the importance of peer feedback, how to use rubrics for peer feedback, manage their time during teamwork, negotiate with team members, and lead a team, among others. Attention also should be paid to providing appropriate training to students for using online applications. Instructors may develop graphics or video materials to assist this purpose. 'Teamwork Training' may add sustainability to MMT through CBL and PBL by facilitating a more concrete engagement and interaction during teamwork. Training may cultivate sustainable grounds on which knowledge is generated as part of a social constructivist framework. Learners are trained to take on active roles, while they participate in diversified teamwork, collaborative learning-by-doing, peer feedback, and continuous case-based assessment.

\subsection{Suggestion 2: Involvement of Pedagogical Mentors}

While MMT through PBL and CBL is sustainable practice inasmuch as it improves students' awareness, critical thinking, and problem solving (Statements 7 to 12), the lack of commitment, failure to share workload equally (Figure 6), lack of punctuality (Figure 7), and other challenges (Table 3) reduce MMT to being an unsustainable method (e.g., Figure 5). Therefore, along with the 'teamwork training' we discussed earlier, an attempt needs to be made to help students identify with the team. To cultivate a team culture with shared values, enhanced cohesion, cooperation, and team spirit, we suggest the involvement of Pedagogical Mentors in Week 3. A Pedagogical Mentor could be an agent, such as a tutor, mentor, coach, motivator, industry, or professional, who can support educational procedures — such as teamwork - at its early stage. For instance, the members of a multicultural team, working on a real-life industry scenario, could participate in a working meeting with an industry professional during the early stages of their teamwork. The industry professional, acting as a pedagogical mentor, can contribute to the teamwork 
process by adding market insights, competitive intelligence, technological expertise, and strategic understanding of business environmental factors; but, most importantly, the addition of 'pedagogical mentors' may mobilize team members to get to work, prior to and after the meeting with the mentor. Valuable information could help the team stick together and work towards a common goal. Pedagogical Mentors may also facilitate learning in virtual environments to improve student engagement in relevant activities.

The involvement of pedagogical mentors will challenge traditional teamwork processes. Unavoidably, students will become involved in new disciplinary and cultural dynamics. As we mentioned earlier, internationalization in education is a positive response to globalization [49]. This method is also likely to help students overcome an inherited fear of the 'Cultural Other' [50]; that is, the fear of issues related to culture, identity, and 'fear of the unknown'. Therefore, 'teamwork training' and 'pedagogical mentors' should not be treated as standalone tools but rather as interconnected mechanisms, with a high degree of interdependence, as part of a sustainable teaching effort.

Finally, the participation of students in 'teamwork training' and the involvement of 'pedagogical mentors' in the process of MMT through CBL and PBL may facilitate a team spirit and the cohesion that is required for enhanced, task-based teamwork [51] at all four levels of the pyramid (Figure 10). In turn, the process will help students develop 21st century learning skills and augment future professional opportunities through sustainable social experiences.

\section{Conclusions}

The present study has investigated the effectiveness of multidisciplinary and multicultural teamwork (MMT) through CBL and PBL pedagogies as a form of sustainable learning. At the same time, within the context of sustainability, the article has explored how this process is supported by existing and developing technologies. This paper has shown that teamwork and collaboration substantially influence student learning-both positively and negatively. For students, certain aspects of teamwork in diversified environments carry a different value. As such, teamwork may both facilitate and hinder sustainable learning. For instance, on the one hand, Case-based and Problem-based Learning in multicultural and multidisciplinary cohorts is sustainable education inasmuch as it improves students awareness, critical thinking, and skills to deal with an issue in the real world. On the other hand, it limits sustainable education. As our findings suggest, CBL and PBL activities, as well as student responsibilities are not favored by all students. To facilitate the sustainable use of MMT through CBL and PBL, we recommend the employment of 'Teamwork Training' and the involvement of 'Pedagogical Mentors', thus improving the sustainability dynamic of the process.

Author Contributions: Conceptualization, E.D., D.K., L.E. and E.E.; methodology, E.D., D.K. and E.E.; software, D.K.; validation, E.D.; formal analysis, E.L., L.E.; investigation, D.K., E.E.; resources, E.D., D.K., L.E. and E.E.; data curation, E.D., D.K., L.E. and E.E.; writing - original draft preparation, E.D., D.K., L.E. and E.E.; writing-review and editing, E.D., D.K., L.E. and E.E.; visualization, E.D., D.K., L.E. and E.E.; supervision, E.D., D.K., L.E. and E.E.; project administration, E.D., D.K., L.E. and E.E.; funding acquisition, N/A. All authors have read and agreed to the published version of the manuscript.

Funding: The research received no external funding.

Institutional Review Board Statement: The study was conducted in line with the International Research Ethics standards, which encompass the protection of participants through informed consent, anonymity and confidentiality of findings; and in line with the research policies of the University of Nicosia, as well as the University's Research Ethics Committee (UREC).

Informed Consent Statement: Informed consent was obtained from all subjects involved in the study.

Data Availability Statement: The data presented in this study are available on request from the corresponding author. The data are not publicly available for confidentiality purposes. 
Conflicts of Interest: The authors declare no conflict of interest.

\section{References}

1. Marra, M.; McCullagh, C. Feeling able to say it like it is: A case for using focus groups in programme evaluation with international cohorts. Int. J. Manag. Educ. 2018, 16, 63-79. [CrossRef]

2. Epaminonda, E.; Ktoridou, D.; Efthymiou, L. Covid-19 contingency plans: The impact on students' future choices. In Proceedings of the 2021 IEEE Global Engineering Education Conference (EDUCON), Vienna, Austria, 21-23 April 2021; SS03B: Special Session Experiential Learning Practices: Vienna, Austria, 2021.

3. Efthymiou, L.; Ktoridou, D.; Epaminonda, E. A model for experiential learning by replicating a workplace environment in virtual classes. In Proceedings of the 2021 IEEE Global Engineering Education Conference (EDUCON), Vienna, Austria, 21-23 April 2021; SS03B: Special Session Experiential Learning Practices: Vienna, Austria, 2021.

4. Hellstén, M.; Reid, A. Researching International Pedagogies: Sustainable Practice for Teaching and Learning; Springer Science+Business Media B.V.: Dordrecht, The Netherlands, 2008.

5. Doukanari, E.; Ktoridou, D.; Epaminonda, E. Multidisciplinary and Multicultural Knowledge Transfer and Sharing in Higher Education Teamworking (1836-1843). In Proceedings of the 2020 Global Engineering Education Conference [EDUCON], Porto, Portugal, 27-30 April 2020; pp. 1836-1843.

6. Varouchas, E.; Sicilia, M.; Sánchez-Alonso, S. Academics' Perceptions on Quality in Higher Education Shaping Key Performance Indicators. Sustainability 2018, 10, 4752. [CrossRef]

7. Ktoridou, D.; Doukanari, E.; Karayiannis, A. Educating the New Generation of Engineer Managers to Stay Relevant in the 21st Century Workforce. In Proceedings of the EDUCON 2019-IEEE Global Engineering Education Conference, Dubai, UAE, 9-11 April 2019; pp. 1575-1579.

8. Chi, Y.; Qin, Y.; Song, R.; Xu, H. Knowledge Graph in Smart Education: A Case Study of Entrepreneurship Scientific Publication Management. Sustainability 2018, 10, 995. [CrossRef]

9. Ktoridou, D.; Doukanari, E.; Epaminonda, E.; Karayiannis, A. Case-Based Learning: Offering a premier targeted learning experience for technology management students. In Proceedings of the 2018 Global Engineering Education Conference [EDUCON] -Emerging Trends and Challenges of Engineering Education (1781-1786), Santa Cruz de Tenerife, Spain, 17-20 April 2018.

10. Carless, D. Differing perceptions in the feedback process. Stud. High. Educ. 2006, 31, 219-233. [CrossRef]

11. Ktoridou, D.; Doukanari, E. Student generated content in higher education technology-related blogs. In Proceedings of the 2015 International Conference on Interactive Mobile Communication Technologies and Learning (IMCL), Thessaloniki, Greece, 19-20 November 2015; pp. 289-295.

12. Boud, D. Sustainable assessment: Rethinking assessment for the learning society. Stud. Contin. Educ. 2000, 22, 151-167. [CrossRef]

13. Geitz, G.; Brinke, D.J.; Kirschner, P.A. Sustainable feedback: Students' and tutors' perceptions. Qual. Rep. 2016, $21,2103-2123$.

14. Doukanari, E. Applying discourse analysis to students' videotaped performances: A recent methodology, a new beginning. In The Foreign Language Classroom: Bridging Theory and Practice; Haggstrom, M.A., Morgan, L.Z., Wieczorek, J.A., Eds.; Garland: New York, NY, USA, 1995; pp. 71-88.

15. Roy, A.; Kihoza, P.; Suhonen, J.; Vesisenaho, M.; Tukiaianen, M. Promoting proper education for sustainability: An exploratory study of ICT enhanced Problem Based Learning in a developing country. Int. J. Educ. Dev. Using Inf. Commun. Technol. 2014, 10, 70-90.

16. Efthymiou, L.; Zarifis, A.; Orphanidou, Y. A measurement model for collaborative online learning in postgraduate engineering management studies. In D. Ktoridou Cases on Engineering Management Education in Practice; IGI Global: Hershey, PA, USA, 2020. [CrossRef]

17. UNESCO. Rewarding Literacy: A Study of the History and Impact of the International Literacy Prices; UNESCO: Paris, France, 2003.

18. Traverso-Ribón, I.; Ruíz-Rube, I.; Dodero, J.; Palomo-Duarte, M. Open data framework for sustainable assessment in software forges. In Proceedings of the 3rd International Conference on Web Intelligence, Mining and Semantics-WIMS '13, Madrid, Spain, 12 January 2013.

19. Barootchi, N.; Keshavarz, M. Assessment of achievement through portfolios and teacher-made tests. Educ. Res. 2002, 44, 279-288. [CrossRef]

20. Daniela, L.; Visvizi, A.; Gutiérrez-Braojos, C.; Lytras, M. Sustainable Higher Education and Technology-Enhanced Learning (TEL). Sustainability 2018, 10, 3883. [CrossRef]

21. Román-Ibáñez, V.; Pujol-López, F.; Mora-Mora, H.; Pertegal-Felices, M.; Jimeno-Morenilla, A. A Low-Cost Immersive Virtual Reality System for Teaching Robotic Manipulators Programming. Sustainability 2018, 10, 1102. [CrossRef]

22. Visvizi, A.; Daniela, L. Technology-Enhanced Learning and the Pursuit of Sustainability. Sustainability 2019, 11, 4022. [CrossRef]

23. Ktoridou, D.; Epaminonda, E.; Karayiannis, A. Multidisciplinary Group Case-Based Learning Environment: An Education Paradigm to Cultivate Entrepreneurial Thinking. In Entrepreneurship, Collaboration, and Innovation in the Modern Business Era; Mehdi, K.P., Ed.; IGI Global: Hershey, PA, USA, 2018; pp. 262-277.

24. Ktoridou, D.; Doukanari, E. Promoting multidisciplinary collaboration through a challenge-based virtual learning environment. In Teaching with Team Projects in Higher Education; Whatley, J., Nerantzi, C., Eds.; Informing Science: Santa Rosa, CA, USA, 2016; pp. 61-70. 
25. Wilson, V.; Pirrie, A. Multidisciplinary Teamworking Indicators for Good Practice; The Scottish Council for Research in Education: Edinburgh, UK, 2000; pp. 1-4.

26. Ktoridou, D.; Dionysiou, I. A Case-Based Learning: An Instructional Model to Incorporate Information Security Topics in Multidisciplinary Courses at the University of Nicosia. In Proceedings of the 2011 IEEE Global Engineering Education Conference (EDUCON), Amman, Jordan, 4-6 April 2011; pp. 466-469.

27. Jackson, S.E. The consequences of diversity in multidisciplinary work teams. In Handbook of Work Group Psychology; West, M.A., Ed.; John Wiley \& Sons: New York, NY, USA, 1996; pp. 53-75.

28. Joachim, S.; Petra, B.S. Thinking in design teams-an analysis of team communication. Des. Stud. 2004, 23, 473-496.

29. Tang, H.H.; Hsiao, E. The advantages and disadvantages of multidisciplinary collaboration in design education. Available online: http:/ / design-cu.jp/iasdr2013/papers/1459-1b.pdf (accessed on 26 December 2019).

30. Efthymiou, L.; Zarifis, A. Modeling students' voice for enhanced quality in online management education. Int. J. Manag. Educ. 2021, 19, 1-16. [CrossRef]

31. Gassmann, O. Multicultural Teams: Increasing Creativity and Innovation by Diversity. Creat. Innov. Manag. 2001, 10, 88-95. [CrossRef]

32. Adler, N. International Dimensions of Organizational Behavior, 4th ed.; South-Western: Cincinnati, OH, USA, 2002.

33. Ktoridou, D.; Eteokleous, N.; Dionysiou, I. Cloud Computing: Providing Tools to Enable Next-generation Case-Based Learning in Undergraduate MIS Courses. In IEEE Technology and Engineering Education, MEEM-Multidisciplinary Engineering Education Magazine, Special Issue on Cloud Computing Technology and Applications; IEEE: Wuhan, China, 2012; Volume 7, pp. 20-27. ISSN 1558-7908.

34. Ktoridou, D.; Eteokleous, N.; Dionysiou, I. Google's applications for undergraduate university courses: Tools for sharing, communication and collaboration. In Didactic Strategies and Technologies for Education: Incorporating Advancements; IGI Global: Hershey, PA, USA, 2013; pp. 632-645.

35. Efthymiou, L.; Orphanidou, Y.; Panayiotou, G. The latest from the tourism front: Technology, innovation and disruption. Eur. Financ. Rev. 2019, 4, 39-43.

36. Efthymiou, L.; Epaminondas, E.; Ktoridou, D. Engineering to management transition: Challenges and how education might assist. In D. Ktoridou Cases on Engineering Management Education in Practice; IGI Global: Hershey, PA, USA, 2020. [CrossRef]

37. Efthymiou, L. Worker body-art in upper-market hotels: Neither accepted, nor prohibited. Int. J. Hosp. Manag. 2018, 74, 99-108. [CrossRef]

38. Bátiz-Lazo, B.; Efthymiou, L. The Book of Payments: Historical and Contemporary Views on the Cashless Economy; Palgrave Macmillan: London, UK, 2016.

39. Bátiz-Lazo, B.; Efthymiou, L. Introduction: The 360 Degrees of Cashlessness. In The Book of Payments: Historical and Contemporary Views on the Cashless Economy; Bátiz-Lazo, B., Efthymiou, L., Eds.; Palgrave Macmillan: London, UK, 2016; pp. 1-10.

40. Bátiz-Lazo, B.; Efthymiou, L. Preface: News from the cashless front. In The Book of Payments: Historical and Contemporary Views on the Cashless Economy; Bátiz-Lazo, B., Efthymiou, L., Eds.; Palgrave Macmillan: London, UK, 2016; pp. ix-xi.

41. Doukanari, E.; Ktoridou, D. Preface. In Fostering Meaningful Learning Experiences Through Student Engagement; Ktoridou, D., Doukanari, E., Eteocleous, N., Eds.; IGI Global: Hershey, PA, USA, 2021. [CrossRef]

42. Harvard Business Publishing Education, Cases. Available online: https://cb.hbsp.harvard.edu/cbmp/pages/content/ casemethodteaching (accessed on 14 November 2019).

43. Holmes, A. Direct Observation. In Encyclopedia of Autism Spectrum Disorders; Volkmar, F.R., Ed.; Springer: New York, NY, USA, 2013.

44. Alred, G.J.; Brusaw, C.T.; Oliu, W.E. Handbook of Technical Writing, 9th ed.; St. Martin's Press: New York, NY, USA, 2009.

45. Schutt, R.K. Investigating the Social World: The Process. and Practice of Research, 4th ed.; Sage Publications: Thousand Oaks, CA, USA, 2004.

46. Wells, W.D.; Sciuto, A.L. Direct observation of purchasing behavior. J. Mark. Res. 1966, 3, 227-233. [CrossRef]

47. Giddens, A. Runaway World: Lecture 1-Globalisation. (6 August 2007). Available online: http://www.bbc.co.uk/radio4/reith1 999/lecture1.shtml (accessed on 28 August 2020).

48. Arthur, N. Counseling International Students: Clients from Around the World; Springer: New York, NY, USA, 2004.

49. Matveev, A.; Milter, R. The value of intercultural competence for performance of multicultural teams. Team Perform. Manag. 2004, 10, 104-111. [CrossRef]

50. Sanderson, G. Existentialism, globalisation and the cultural other. Int. Educ. J. 2004, 4, 1-20.

51. Ktoridou, D.; Doukanari, E. Task-Based Internships: Fostering Ideal Learning through Focused Experience. In Proceedings of the 2017 Global Engineering Education Conference [EDUCON] — Challenging the Transition from the Classic to the Emerging in the Engineering Education, Athens, Greece, 25-28 April 2017; pp. 1717-1722. 